\title{
Cognitive Impairment in Epilepsy: A Clinical Study
}

\author{
Siddharth Shetty A ${ }^{1}$, P John Mathai ${ }^{2}$. \\ ${ }^{1,2}$ Department Of Psychiatry, Father Muller Medical College, Mangalore, Karnataka, India
}

\begin{abstract}
:
Background: Patients with epilepsy have relatively higher risk for psychopathology and cognitive impairment. The research data indicate that the cognitive impairment and deterioration are due to associated brain damage and not attributable to epilepsy. The objective of the current study is to evaluate the cognitive functions in patients with adequate seizure control, without obvious brain damage and to compare with healthy first degree relatives.
\end{abstract}

Method:This is a cross sectional case control study conducted in Father Muller Medical College Mangalore. A total of 80 subjects, 40 patients attending the outpatient and inpatient facilities of the department of Neurology with a clinical diagnosis of idiopathic generalized tonic clonicepilepsy and 40 healthy age matched first degree relatives were evaluated. Tools used were Standardized Mini Mental Status Examination, Brief Cognitive Rating Scale, Trail Making Test-B and Digit Symbol Substitution Test for evaluation of cognitive functions. The various findings were statistically analyzedusing chi- square test,Student T test and ANOVA.

Results: Patients with epilepsy showed significant cognitive impairment in TMT-B and DSST when compared with control.Patients with epilepsy committed more number of errors on these tests. Socio-demographic variables and clinical variables like age, education, socio-economic class, occupation and duration of epilepsy had significant correlation with worse cognitive functioning.

Conclusions: Adult individuals with well controlled idiopathic generalized tonic clonic epilepsy without obvious structural brain damage have cognitive impairment compared to healthy first degree relatives.

Keywords: Cognitive function, Epilepsy.

\section{Introduction}

Epilepsy is the most common primary disorder of the brain, known to be second only todepression as causing neuropsychiatric disability worldwide. ${ }^{1}$ Some studies have noted that symptomatic epilepsy with preexisting brain damage is known to cause cognitive impairment, while others argue that, while pre-existing brain damage is an important variable, it does not entirely explain the neuropsychological deficits, there appears to be an 'epilepsy factor' which leads to such deficits. ${ }^{2,3}$ Two groups of epilepsy related factors have been widely accepted to influence cognition, morphological features like inborn or acquired lesions, which are either stable or progressive and tend to cause irreversible impairment; and functional changes like interictal discharges, seizures, and anticonvulsant drugs with fluctuating and potentially reversible effects on cognition. ${ }^{4}$ Several variables have been implicated in the development of cognitive deficits, including age at onset, nature of seizures, location of seizure foci, duration of seizure free period, use of antiepileptic drugs and epilepsy related surgery. ${ }^{5,6,7,8}$ Other studies have focused on cognitive performance at disease onset and found that individuals with epilepsy performed worse than siblings or normal controls on several neuropsychological tests. ${ }^{9,10,11,12}$ The domains of cognition most often affected include attention and concentration, language, memory, intelligence, executive functions, motor speed and visuo-spatial processing speed. ${ }^{13,14}$

Patients with epilepsy showed impaired sustained attention on vigilance tasks. ${ }^{15,16,17}$ Delaney and colleagues concluded that interictal memory deficits are often found in patients with generalized or complex partial seizures, especially with left or bilateral temporal onset. ${ }^{18}$ Hermann et al found that verbal memory impairment was usually seen in left temporal seizure patients, but nonverbal or visual memory deficits were more difficult to lateralize. ${ }^{19}$ Word finding difficulty or even clinical anomia occurred in patients with left temporal lobe seizures. Anomia and other language dysfunction, such as aural comprehension deficits, may account for some of the verbal memory deficits associated with temporal lobe seizures. ${ }^{20,21}$ Complex problem solving and cognitive flexibility were often impaired in epilepsy. ${ }^{22}$ Patients with epilepsy had lengthened reaction times, as well as slowing of pure motor speed. ${ }^{23}$ Dodrill and Wilkusconcluded that perceptual functions, such as response to double simultaneous stimulation, graphaesthesia and finger gnosis were not impaired in most forms of epilepsy.Impaired tactile perception may occur in patients with GTCS of greater frequency or with generalized EEG slowing. ${ }^{24}$ Smith et al found impaired motor speed and coordination to be common in epilepsy especially in patients with GTCS, mixed seizure types and various EEG abnormalities. ${ }^{25}$ Mazzucchi et al found that laterality affected perceptual ability with left temporal seizures disrupting dichotic linguistic material and right seizures disrupting nonlinguistic auditory perception. ${ }^{26}$ Tayloret al found no deficits in 
visuospatial abilities. ${ }^{27}$ Dodrillet al found impaired spatial analysis and constructional ability to occur in epilepsy patients. ${ }^{28}$ Weglage and co-workers and Croona and co-workers demonstrated that when compared with controls, children with this syndrome are impaired, particularly in IQ, memory, visual perception, verbal fluency, and fine motor skills. ${ }^{29,30}$

Generalized tonic clonic seizures, especially if status epilepticus occurs are more likely to impair cognition than simple and complex partial seizures. ${ }^{9,31}$ Patients with partial onset of seizures did not differ from patients with generalized seizures in tests of motor function or attention, nor in tests of learning and memory. ${ }^{10,32}$ Patients with epilepsy performed significantly worse on visual motor tasks, mental flexibility and in delayed visual memory. ${ }^{10}$ Patients with juvenile myoclonic epilepsyshowed deficits in attention, immediate verbal memory, mental flexibility, control of inhibition, working memory, processing speed, verbal delayed memory, visual delayed memory, naming, and verbal fluency. The duration of epilepsy correlated with cognitive decline, and patients with higher education manifested less progression of deficits. ${ }^{33,34,35,36}$ Patients with LennoxGastaut syndrome also have rapid and progressive cognitive decline and cognitive outcome is worse for patients with early disease onset. ${ }^{37,38}$ Childhood onset absence epilepsy had subtle cognitive deficits and duration of illness, seizure frequency, antiepileptic drug treatment were related to the severity of the cognitive deficits. ${ }^{11,39}$ Patients with idiopathic occipital lobe epilepsy scored worse than controls in intellectual functioning, memory, and attention. ${ }^{40}$

Deficits in motor skills, response inhibition, attention, working memory, planning, and psychomotor speed were noted in patients with Temporal lobe epilepsy. ${ }^{41,42}$ Left sided Temporal lobe epilepsy in general is characterized by material specific verbal memory deficits, particularly in long term consolidation and retrieval. ${ }^{43}$ In a selected subgroup of patients with right TLE with hippocampal sclerosis, a specific visual memory deficit was found. ${ }^{44}$ Left sided TLE is commonly associated with impaired verbal learning, short term or working memory and right sided temporal lobe system with nonverbal memory ${ }^{45}$ but corresponding findings are less consistent ${ }^{46}$. Patients with temporal lobe epilepsy deficits were noted in phonological, semantic and verbal working memory. ${ }^{47}$ Patients with chronic partial epilepsy demonstrated deficits on overall cognition and verbal memory that generally are not progressive. ${ }^{48,49}$ Mirsky and co-workers studied idiopathic generalized epilepsy with JME and found that both subgroups of patients were found to be impaired in visual and auditory sustained attention. ${ }^{5}$ Patients with idiopathic generalized epilepsy performed significantly poorer in non-verbal and verbal attention, verbal learning and memory, word fluency, and controlled sequential fine motor responses excluding non-verbal memory. ${ }^{47,50,51}$ Patients with idiopathic generalized epilepsy, early seizure onset prior to 18 years was a powerful predictor of neuropsychological impairment. ${ }^{7,85}$ There are several reports about the cognitive impairment and cognitive deterioration in patients with epilepsy. The research data indicate that the cognitive impairment and deterioration are due to associated brain damage and not attributable to Epilepsy. There are only a limited number of studies investigating the cognitive impairment in uncomplicated epilepsy, with good seizure control and without obvious structural brain damage. Aims of the study wereto evaluate the frequency and nature of the cognitive impairment in patients with epilepsy and to evaluate the relationship between sociodemographic and clinical variables and cognitive impairment in patients with epilepsy.

\section{Materials And Method}

The clinical study was conducted in Father Muller Medical College, Mangalore. All patients attending the outpatient and inpatient facilities of the department of Neurology with a clinical diagnosis of idiopathic generalized tonic clonicepilepsy constituted the population for the study. The study was conducted from the $1^{\text {st }}$ of September 2007 to the $31^{\text {st }}$ of August 2009.

The sample for the study consisted of forty consecutive patients with idiopathic generalized tonic clonic epilepsy who satisfied the inclusion and exclusion criteria. Inclusion Criteria weremale and female patients between the ages of 18 and 50yrs with atleast primary school education. Patients diagnosed with idiopathic generalized tonic clonic epilepsy with duration of illness less than 10 years. Exclusion Criteria werepatients with comorbid neuro psychiatric disorders, patients with epilepsy secondary to other causes, intractable epilepsy or with poor seizure control and patients with epilepsy who have undergone neuro surgical interventions, patients with epilepsy having medical disorders like diabetes mellitus, thyroid and other endocrine disorders and other chronic debilitating medical conditions known to cause cognitive impairment and patients on long term regular treatment other than antiepileptic drugs.

Forty first degree male and female non affected relatives of the patients between the ages of $18-50 \mathrm{yrs}$ without comorbid psychopathology constituted the control for the study.

\section{Procedure}

A written informed consent was obtained from all patients and the first degree relatives recruited for the study. This study has been cleared by the ethical committee of the institution. The socio demographic and clinical variables were recorded in a specific proforma prepared for this clinical study. All the patients and 
control underwent a through clinical examination to rule out psychopathology and medical disorders if any. The cognitive functions of patients in the clinical sample, and subjects in the control group were assessed using Standardized mini mental status examination, Digit symbol substitution test, Trail making test B, Brief cognitive rating scale.The patients with epilepsy were evaluated during the interictal period at least six weeks after the last seizure. The data was analyzed using chi- square test, Student T test and ANOVA.

\subsection{Sociodemographic characteristics}

\section{Results}

40 cases of idiopathic generalized tonic clonic epilepsy and 40 age matched first degree relatives were assessed. Table 1 shows the distribution of demographic characteristics in both groups. Age wise comparison reveals that increasing age has a negative effect on cognitive functions, with the age group of 30-50 years performing worse than age group of 18-30 years on BCRS, TMT-Band DSST. The cases group show significant difference on SMMSE ( $\mathrm{p}=0.002)$ with cases having lower mean score (24.80) in the 30-50years group compared to 18-30 years group (27.90). Based on education, highly significant differences are found in the SMMSE in both cases and control group. Higher mean scores are achieved by subjects who have studied beyond primary level: PUC (29.11 and 29.66), graduation (29.66 and 30) and high school (25.83 and 25.76). Statistically significant difference $(\mathrm{p}=0.002)$ is found in BCRS for cases. Highly significant difference is found on TMT-B total time and errors $(\mathrm{p}=0.000)$ for both cases and control group. DSST total time is highly significant for the cases group ( $\mathrm{p}=0.000)$ where as DSST error is highly significant in both cases and control group $(\mathrm{p}=0.000)$. These results indicate that subjects with lower education up to the primary level only, fared worse on all cognitive tests conducted in this study. Occupation based data shows statistically significant differences on SMMSE for both cases (0.039) and control (0.006), with unskilled labour group scoring lowest mean scores (25.11 and 25.16 respectively). TMT-B total time is significant for cases $(\mathrm{p}=0.04)$, and TMT-B error is significant for both cases (0.02) and control group (0.024) DSST total time and error is significant in the cases group (0.01). This indicates poorer cognitive functions in the unskilled labour group. Socio-economic class has a significant influence on cognitive functioning. People belonging to the lower Socio-Economic class performed poorly on SMMSE, BCRS, TMT-B and DSST compared to middle and upper Socio-Economic class subjects.

$55 \%$ of patients had epilepsy for duration of 1-2 years forming the largest group, followed by $32.5 \%$ of patient that had epilepsy onset within one year. There is no significant difference between the groups. 55\% of patients were seizure free for a period of 1-2 years, 32.5\% of patients were seizure free for $>6$ weeks but less than 1 year and $12.5 \%$ of patients were seizure free for longer durations (2-10 years). There is no significant difference between the groups. ( $\mathrm{p}=0.562)$ [Table 2].Data based on duration of epilepsy shows that subjects with longest duration of epilepsy ( $>10$ years) performed poorly on all cognitive functions tests. There is no statistical significance found for the duration of seizure free interval.

On SMMSE there is a significant difference in the mean scores with respect to construction $(\mathrm{p}=0.043)$ between the cases and control group. However no statistically significant difference is found in the domains of orientation $(\mathrm{p}=0.320)$, registration, attention and concentration $(0.658)$, recall and language $(\mathrm{p}=0.573)$. There is no significant difference between cases and control on the total SMMSE score $(\mathrm{p}=0.461)$, the mean score attained by the cases is 27.13 and that by the control group is 27.60 a score below 24 on the SMMSE indicates cognitive deficits.On BCRS statistically significant difference is found in the domain of concentration between cases and control group ( $\mathrm{p}=0.027)$, cases have a higher mean value (1.80) compared to control group (1.38), which indicates impairment in concentration. There is no significant difference found in domains of recent memory, past memory, orientation and functioning and self-care.There is a significant difference in the total score of BCRS between cases and control group ( $\mathrm{p}=0.023)$. The cases have a higher mean value (1.165) compared to control group (1.075), indicating cognitive impairment in the cases group.

In The Trail Making Test B, there is no significant difference between cases and control group in time taken to complete the TMT-B test $(\mathrm{p}=0.586)$. Statistically significant difference is found in the number of errors committed on TMT-B test between the cases and control group $(\mathrm{p}=0.023)$. The cases have a higher mean value (0.75) compared to the control group (0.33), indicating cognitive impairment in the cases group. In the DSST there is no significant difference between the two groups in time taken to complete the DSST $(\mathrm{p}=0.441)$. There is statistically significant difference between the two groups in the number of errors committed on the DSST $(\mathrm{p}=0.003)$. The mean value for cases (1.28) being higher than the mean value for control group (0.50), this indicates cognitive impairment in the cases group compared to the control group.[Table 3]

\section{Discussion}

Cognitive impairment and cognitive deterioration have been described as a complication of epilepsy by several authors. The results of the present study indicate that there is significant cognitive impairment in patients with idiopathic GTCS. This cognitive impairment is limited to construction abilities in SMMSE, concentration in BCRS, attention, sequential abilities, motor function and executive functions in TMT-B and visuo-motor 
coordination, sustained attention and response speed in DSST. However there are no cognitive deficits as indicated by SMMSE and BCRS. Earlier investigators reported consistent cognitive impairment in patients with epilepsy $5,29,33,3440$

Earlier investigators evaluated cognitive impairment in patients with epilepsy with brain damage and other complications. The present investigators studied exclusively a group of patients with GTCS not associated with brain damage or other factors which could produce cognitive impairment. The other investigators explained that the cognitive impairment could be attributed to brain damage, age of onset of epilepsy, nature and location of seizure focus, duration of epilepsy, anticonvulsant drugs and epilepsy related surgery ${ }^{5,6,7,8}$ Few earlier studies reported that there is significant cognitive impairment in patients with idiopathic GTCS without brain damage. ${ }^{10,11}$ The cognitive impairment could be due to subtle brain damage which the present investigators could not exclude with neurological and neuropsychological investigations. The apparent cognitive impairment could be the result of impairment in concentration (BCRS). It is more likely that there could be cognitive impairment in epilepsy as such without brain damage. The cognitive impairment could be attributed to socio economic class, education and occupation as found by the study. The adverse effects of antiepileptic drugs have not been evaluated in this study and it could be a possible explanation for the cognitive impairment evidenced. A significant relationship has been found with the duration of epilepsy. The SMMSE and BCRS show no evidence of cognitive deficits and subtle impairment has been found on TMT-B and DSST.

In this study statistically significant difference is found in the domain of concentration $(\mathrm{p}=0.027)$ and total BCRS score $(\mathrm{p}=0.023)$. The cases group have higher mean score values indicating cognitive impairment in this group.TMT-B is a test of attention, visual scanning and sequential abilities, mental flexibility, motor function and executive function, this test has been used frequently in earlier studies. In this study there is no significant difference in time taken to complete the test between cases and control, but cases committed twice as many errors and this is statistically significant $(\mathrm{p}=0.023)$, thus TMT-B revealed presence of cognitive impairment in cases. TMT-B is more sensitive to cognitive dysfunction than SMMSE and hence its use helps to detect subtle cognitive decline.DSST is a timed test of attention, psychomotor performance and perceptual organization. Earlier studies have utilized this test on a frequent basis. In this study there is no significant difference between cases and control in time taken to complete the DSST, significant difference $(\mathrm{p}=0.003)$ is found in the number of errors made. The cases group made more than twice as many errors as the control group.

In this study, age is inversely proportional to cognitive functioning. Increasing age revealed worse cognitive functioning in both the cases and control group.Males form $60 \%$ of the sample size and Females $40 \%$. Based on gender there is no statistically significant difference between cases and control in cognitive functions.Earlier studies did not stratify subjects by religion, though some studies have conducted neuropsychological tests in certain ethnic groups and races ${ }^{53,54}$ Religion is one of the socio-demographic variables considered in this study. Majority of the sample comprised of Hindus (55\%), followed by Christians $(35 \%)$ and Muslims (10\%). Religion did not have any statistically significant bearing on cognitive functioning in this study.All participants in this study had completed primary school education. 41 subjects $(51.3 \%)$ had received more than 12 years of formal education. In this study there is evidence of worse cognitive functioning in subjects with less number of years of education in both cases and control group which is in agreement with previous studies. Moreover individuals with epilepsy tend to discontinue education early due to disability, or show poor scholastic performance due to cognitive decline ${ }^{39,47,50}$ Earlier studies have not included occupation and Socio-Economic class as variables. This study shows that subjects belonging to the lower Socio-Economic group and having unskilled labour have cognitive impairment when compared to subjects in the middle and upper economic class. This study included marital status, domicile and type of family as socio-demographic variables, these variables did not have any statistical significance.

This study included duration of epilepsy as a clinical variable. Majority of the subjects (22 subjects: $55 \%$ ) had epilepsy for a duration of 1-2 years. Individuals with more than 5 years of epilepsy formed only $2.5 \%$ of the cases group. Earlier studies have noted that longer duration of epilepsy has a significant effect on cognitive functioning. In this study it is seen that seizure duration of more than 5 years is associated with worse cognitive outcome. This result may be biased by the relatively small number of individuals with epilepsy duration more than 5 years, nevertheless there is evidence of cognitive decline with longer duration of epilepsy. In this study duration of seizure free interval did not have any statistical significance, which is in contrast to earlier studies. $5,6,7,8,49$

The present investigation has several limitations and certain relative merits. The samples as well as the control are not representative of the general population. Recruitment of consecutive patients ensures that there is no sample bias. The exclusion and inclusion criteria are specific. Hence the sample consists of generalized tonic clonic epilepsy patients who are otherwise not compromised, but this has not been verified by using neurological investigations to exclude presence of such factors. The effect of antiepileptics and other medications has not been considered in this study. The sample consists of only GTCS and excludes other types of epilepsy, particularly CPS which is known to be associated with cognitive impairment and psychopathology. 
The present investigation has only one control group of healthy first degree relatives. The size of the sample and control is sufficient to calculate the prevalence and nature of cognitive impairment, but a larger sample size will be required to enhance the reliability and validity of the results. A larger sample size is required to calculate the exact relationship of cognitive impairment and socio-demographic and clinical variables. The present study is a cross sectional case control study examining the cognitive impairment in GTCS. A longitudinal study would enable to assess the stability of cognitive deficits. The tools used have adequate established reliability and validity. All the tools are rater friendly, easy to administer, less time consuming thereby causing no discomfort to the patients. The use of SMMSE and BCRS are unique to the present study.

\section{Conclusion}

Statistically significant differences are found on TMT-B and DSST between cases and control in the number of errors committed, indicating cognitive impairment in cases group.Increasing Age, lower levels of Education and Occupation and low Socio-Economic status have negative effect on cognitive functions. The current study concludes that in adult patients with well controlled generalized tonic clonic epilepsy, without obvious structural brain damage there is significant cognitive impairment.

\section{Clinical Implications}

This study has found that adult patients with well controlled generalized tonic clonic epilepsy, without obvious structural brain damage have significant cognitive impairment. Hence assessment of cognitive functions is warranted for comprehensive management of patients with epilepsy.

\section{References}

[1]. Lishman W.A. Epilepsy. In: Organic Psychiatry- The Psychological consequences of cerebral disorder. $3^{\text {rd }}$ edition. Blackwell Science 2004; 237-314.

[2]. Graham P and Rutter M. Organic brain dysfunction and child psychiatric disorder. British Medical Journal 1968; 3: 695-700.

[3]. Gagliano A, Ferlazzo E, Germanò E, Calarese T, Magazù A, Sferro C, Tortorella G. Neuropsychological deficits in monozygotic twins with childhood epilepsy with occipital paroxysms.JClinExpNeuropsychol. 2007;29(5):488-95.

[4]. Elger CE, Helmstaedter C, Kurthen M. Chronic epilepsy and cognition. Lancet Neurol 2004;3(11):663-72.

[5]. Mirsky AF, Duncan CC and Levav M. Neuropsychological studies in idiopathic generalized epilepsies. In: Neuropsychology of childhood epilepsies, EdsJambaque I, Lassonde M and O Dulac, New York: Kluwer Academic 2001;141-150.

[6]. Dodrill CB. Progressive cognitive decline in adolescents and adults with epilepsy. Prog Brain Res 2002;135:399-407.

[7]. Jokeit $\mathrm{H}$ and Ebner A. Long term effects of refractory temporal lobe epilepsy on cognitive abilities: a cross sectional study. J NeurolNeurosurg Psychiatry 1999;67(1):44-50.

[8]. Jokeit $\mathrm{H}$ and Ebner A. Effects of chronic epilepsy on intellectual functions. Prog Brain Res 2002;135:455-63.

[9]. Prevey ML, Delaney RC, Cramer JA, Mattson RH. Complex partial and secondarily generalized seizure patients: cognitive functioning prior to treatment with antiepileptic medication. VA Epilepsy Cooperative Study 264 Group. Epilepsy Res 1998;30(1):1-9.

[10]. Pulliainen V, Kuikka P, Jokelainen M. Motor and cognitive functions in newly diagnosed adult seizure patients before antiepileptic medication. ActaNeurolScand 2000;101(2):73-80.

[11]. Fastenau PS, Johnson CS, Perkins SM, Byars AW, deGrauw TJ, Austin JK, Dunn DW. Neuropsychological status at seizure onset in children: risk factors for early cognitive deficits. Neurology 2009;73(7):526-34.

[12]. Perrine K, Gershengorn J, Brown E. Interictal neuropsychological function in epilepsy. In: Epilepsy and Behavior. EdsDevinsky O, Theodore W. New York: Wiley-Liss 1991; 181-193.

[13]. Perrine K and Kiolbasa T. Cognitive deficits in epilepsy and contribution to Psychopathology Neurology 1999;53(5): S39-S48.

[14]. Meador KJ. Cognitive outcomes and Predictive factors in epilepsy. Neurology 2002;58 (5): S21-S26.

[15]. Fedio P and Mirsky AF. Selective intellectual deficits in children with temporal lobe or centrencephalic epilepsy. Neuropsychologia 1969; 7: 267-300.

[16]. Stores G, Hart J, Piran N. Inattentiveness in schoolchildren with epilepsy. Epilepsia 1978; 19: 169-175.

[17]. Binnie CD. Detection of transitory cognitive impairment during epileptiform EEG Discharges: Problems in clinical practice. In: Epilepsy and Behaviour. EdsKulig BM, Meinardi H, Stores G. Lisse: Swets and Zeitlinger 1980; 91-97.

[18]. Delaney RC, Prevey ML, Mattson RH. Short term retention with lateralized temporal lobe epilepsy. Cortex 1986; 22: 591-600.

[19]. Hermann BP, Wyler AR, Richey ET, Rea JM. Memory function and verbal learning ability in Patients with complex partial seizures of temporal lobe origin. Epilepsia 1987; 28: 547-554.

[20]. Ross ED and Mesulam MM. Dominant language functions of the right hemisphere. Arch Neurol 1979; 36: $144-148$.

[21]. Mayeux R, Brandt J, Rosen J, Benson DF. Interictal memory and language impairment in temporal lobe epilepsy. Neurology 1980; 30: $120-125$.

[22]. Dikmen S and Matthews C. Effect of major motor seizure frequency upon cognitive-intellectual functions in adults. Epilepsia 1977; 18: 21-29.

[23]. Bruhn P and Parsons OA. Continuous reaction time in brain damage. Cortex 1971; 7: 278-291.

[24]. Dodrill CB and Wilkus RJ. Neuropsychological correlates of the Electroencephalogram in epileptics: III. Generalized nonepileptiform abnormalities. Epilepsia 1978; 19: 453-462.

[25]. Smith DB, Craft BR, Collins J, Mattson RH, Cramer JA. Behavioral characteristics of epilepsy Patients compared with normal controls. Epilepsia 1986; 27: 760-768.

[26]. Mazzucchi A, Visintini D, Magnani G, Cattelani R, Parma M. Hemispheric prevalence changes in partial epileptic patients on perceptual and attentional tasks. Epilepsia 1985; 26:379-390.

[27]. Taylor LB. Localization of cerebral lesions by psychological testing. ClinNeurosurg 1969; 16: 269-287.

[28]. Dodrill CB. A Neuropsychological battery for epilepsy. Epilepsia 1978; 19: 611-623.

[29]. Weglage J, Demsky A, Pietsch M, Kurlemann G. Neuropsychological, intellectual, and behavioral findings in patients with centrotemporal spikes with and without seizures. Dev Med Child Neurol 1997 oct; 39: 646-651.

\begin{tabular}{|c|c|}
\hline DOI: $10.9790 / 0853-1602060410$ & Www.iosriournals.org \\
\hline
\end{tabular}


[30]. Croona C, Kihlgren M, Lundberg S, Eeg-Olofsson O, Eeg-Olofsson KE. Neuropsychological findings in children with benign childhood epilepsy with centrotemporal spikes. Dev Med Child Neurol. 1999;41(12):813-818.

[31]. Dodrill CB. Neuropsychological effects of seizures. Epilepsy Behav 2004; 5(1): S21-40.

[32]. Bhise VV, Burack GD, Mandelbaum DE. Baseline cognition, behavior, and motor skills in children with new-onset, idiopathic epilepsy. Dev Med Child Neurol 2010;52(1):22-26.

[33]. Pascalicchio TF, de Araujo Filho GM, da Silva Noffs MH, Lin K, Caboclo LO, Vidal-Dourado M, Ferreira Guilhoto LM, Yacubian EM. Neuropsychological profile of patients with juvenile myoclonic epilepsy: a controlled study of 50 patients. Epilepsy Behav 2007 Mar; 10(2): 263-67

[34]. Swartz BE, Simpkins F, Halgren E, Mandelkern M, Brown C, Krisdakumtorn T, Gee M. Visual working memory in primary generalized epilepsy: an 18FDG-PET study. Neurology 1996 Nov; 47(5): 1203-12.

[35]. Devinsky O, Gershengorn J, Brown E, Perrine K, Vazquez B, Luciano D. Frontal functions in juvenile myoclonic epilepsy. Neuropsychiatry NeuropsycholBehavNeurol 1997; 10(4): 243-6.

[36]. Savic I, Lekvall A, Greitz D, Helms G. MR spectroscopy shows reduced frontal lobe concentrations of N-acetyl aspartate in patients with juvenile myoclonic epilepsy. Epilepsia 2000; 41(3): 290-296.

[37]. Jambaque I, Mottron L, Chiron C. Neuropsychological outcome in children with West syndrome: a "human model" for autism. In: Neuropsychology of childhood epilepsies, EdsJambaque I, Lassonde M, O Dulac. New York: Kluwer Academic 2001; 175-183.

[38]. Tartar R. Intellectual and adaptive functioning in epilepsy: a review of 50 years of research. Dis NervSyst 1972; 33: 763-770.

[39]. Caplan R, Siddarth P, Stahl L, Lanphier E, Vona P, Gurbani S, Koh S, Sankar R, Shields WD. Childhood absence epilepsy: behavioral, cognitive, and linguistic comorbidities. Epilepsia 2008; 49(11): 1838-46.

[40]. Saint-Martin AD, Seegmuller C, Carcangiu R, Kleitz C, Hirsch E, Marescaux C, Metz-Lutz MN. Cognitive consequences of Rolandic Epilepsy. Epileptic Disord 2001;3(2): SI59-65.

[41]. Helmstaedter C, Elger CE. Cognitive consequences of two-thirds anterior temporal lobectomy on verbal memory in 144 patients: a three-month follow-up study. Epilepsia 1996; 37(2): 171-80.

[42]. Helmstaedter C, Hauff M, Elger CE. Ecological validity of list-learning tests and self-reported memory in healthy individuals and those with temporal lobe epilepsy. J ClinExpNeuropsychol 1998; 20(3): 365-75.

[43]. Hermann BP, Seidenberg M, Schoenfeld J, Davies K. Neuropsychological characteristics of the syndrome of mesial temporal lobe epilepsy. Arch Neurol 1997; 54(4): 369-76.

[44]. Gleissner U, Helmstaedter C, Elger CE. Right hippocampal contribution to visual memory: a presurgical and postsurgical study in patients with temporal lobe epilepsy. J NeurolNeurosurg Psychiatry 1998; 65(5): 665-69.

[45]. Spanaki MV, Kopylev L, DeCarli C, Gaillard WD, Liow K, Fazilat S, Fazilat S, Reeves P, Sato S, Kufta C, Theodore WH. Postoperative changes in cerebral metabolism in temporal lobe epilepsy. Arch Neurol 2000; 57(10): 1447-52.

[46]. Alessio A, Kobayashi E, Damasceno BP, Lopes-Cendes I, Cendes F. Evidence of memory impairment in asymptomatic individuals with hippocampal atrophy. Epilepsy Behav 2004; 5(6): 981-87.

[47]. Chaix Y, Laguitton V, Lauwers-Cancès V, Daquin G, Cancès C, Démonet JF, Villeneuve N. Reading abilities and cognitive functions of children with epilepsy: influence of epileptic syndrome. Brain Dev 2006; 28(2): 122-30

[48]. Bjørnaes H, Stabell K, Henriksen O, Løyning Y. The effects of refractory epilepsy on intellectual functioning in children and adults. A longitudinal study. Seizure 2001; 10(4): 250-59.

[49]. Griffith HR, Martin RC, Bambara JK, Marson DC, Faught E. Older adults with epilepsy demonstrate cognitive impairments compared with patients with amnestic mild cognitive impairment. Epilepsy Behav 2006 Feb; 8(1): 161-68

[50]. Oostrom KJ, van Teeseling H, Smeets-Schouten A, Peters AC, Jennekens-Schinkel A. Three to four years after diagnosis: cognition and behaviour in children with 'epilepsy only'. A prospective, controlled study Brain. 2005; 128(7): 1546-55.

[51]. Caplan R, Siddarth P, Stahl L, Lanphier E, Vona P, Gurbani S, Koh S, Sankar R, Shields WD. Childhood absence epilepsy: behavioral, cognitive, and linguistic comorbidities. Epilepsia 2008; 49(11): 1838-

[52]. Hessen E, Lossius MI, Reinvang I, Gjerstad L. Predictors of neuropsychological impairment in seizure-free epilepsy patients. Epilepsia 2006; 47(11): 1870-80

[53]. Kertzman S, Ben-Nahum Z, Gotzlav I, Grinspan H, Birger M, Kotler M. Digit Symbol Substitution test performance: sex differences in a Hebrew-readers' health population. Percept Mot Skills 2006; 103(1): 121-30.

[54]. Imam I, Ogunniyi A. The value of the mini mental state examination in Nigerian epileptics. Trop Doct 2005; 35(2): 108-9.

Table 1: Socio-Demographic Characteristics

\begin{tabular}{|c|c|c|c|c|}
\hline Demographic Data & Cases & Control & Total & $\mathrm{P}$ value \\
\hline \multicolumn{5}{|l|}{ Age } \\
\hline \multirow{3}{*}{$\begin{array}{l}18-30 \mathrm{yrs} \\
30-40 \mathrm{yrs} \\
40-50 \mathrm{yrs}\end{array}$} & \multirow{3}{*}{$\begin{array}{c}30(75 \%) \\
8(20 \%) \\
2(5 \%) \\
\end{array}$} & $27(67.5 \%)$ & $57(71.3 \%)$ & \multirow[t]{3}{*}{0.643} \\
\hline & & $9(22.5 \%)$ & $17(21.3 \%)$ & \\
\hline & & $4(10 \%)$ & $6(7.5 \%)$ & \\
\hline \multicolumn{5}{|l|}{ Gender } \\
\hline \multirow{2}{*}{$\begin{array}{c}\text { Male } \\
\text { Female }\end{array}$} & $22(55 \%)$ & $26(65 \%)$ & $48(60 \%)$ & \multirow[t]{2}{*}{0.361} \\
\hline & $18(45 \%)$ & $14(35 \%)$ & $32(40 \%)$ & \\
\hline \multicolumn{5}{|l|}{ Religion } \\
\hline \multirow{3}{*}{$\begin{array}{c}\text { Hindu } \\
\text { Christian } \\
\text { Muslim } \\
\end{array}$} & $22(55 \%)$ & $22(55 \%)$ & $44(55 \%)$ & \multirow[t]{3}{*}{0.929} \\
\hline & $14(35 \%)$ & $14(35 \%)$ & $14(35 \%)$ & \\
\hline & $4(10 \%)$ & $4(10 \%)$ & $4(10 \%)$ & \\
\hline \multicolumn{5}{|l|}{ Education } \\
\hline \multirow{4}{*}{$\begin{array}{c}\text { Primary } \\
\text { High school } \\
\text { Puc/Graduation } \\
\text { Post Graduation }\end{array}$} & $8(20 \%)$ & $6(15 \%)$ & $14(17.5 \%)$ & \multirow[t]{4}{*}{0.694} \\
\hline & $12(30 \%)$ & $13(32.5 \%)$ & $25(31.3 \%)$ & \\
\hline & $17(42.5 \%)$ & $15(37.5 \%)$ & $32(40 \%)$ & \\
\hline & $3(7.5 \%)$ & $6(15 \%)$ & $9(11.3 \%)$ & \\
\hline \multicolumn{5}{|l|}{ Occupation } \\
\hline \multirow{2}{*}{$\begin{array}{c}\text { Unemployed } \\
\text { Unskilled }\end{array}$} & $1(2.5 \%)$ & $3(7.5 \%)$ & $4(5 \%)$ & \multirow[t]{2}{*}{0.760} \\
\hline & $5(12.5 \%)$ & $4(10 \%)$ & $9(11.3 \%)$ & \\
\hline
\end{tabular}


Cognitive Impairment in Epilepsy: A Clinical Study

\begin{tabular}{|c|c|c|c|c|}
\hline \multirow{4}{*}{$\begin{array}{c}\text { Skilled } \\
\text { Clerk/office } \\
\text { Agriculturist } \\
\text { Others }\end{array}$} & $4(10 \%)$ & $6(15 \%)$ & $10(12.5 \%)$ & \\
\hline & $7(17.5 \%)$ & $5(12.5 \%)$ & $12(15 \%)$ & \\
\hline & $3(7.5 \%)$ & $6(15 \%)$ & $9(11.3 \%)$ & \\
\hline & $17(42.5 \%)$ & $13(32.5 \%)$ & $30(37.5 \%)$ & \\
\hline \multicolumn{5}{|l|}{ Marital status } \\
\hline \multirow{3}{*}{$\begin{array}{c}\text { Single } \\
\text { Married } \\
\text { Separated/divorced }\end{array}$} & $22(55 \%)$ & $23(57.5 \%)$ & $45(56.3 \%)$ & \multirow[t]{3}{*}{0.466} \\
\hline & $18(45 \%)$ & $16(40 \%)$ & $34(42.5 \%)$ & \\
\hline & $0(0 \%)$ & $1(2.5 \%)$ & $1(1.3 \%)$ & \\
\hline \multicolumn{5}{|l|}{ Type of Family } \\
\hline \multirow{3}{*}{$\begin{array}{c}\text { Nuclear } \\
\text { Extended Nuclear } \\
\text { Joint }\end{array}$} & $30(75 \%)$ & $32(80 \%)$ & $62(77.5 \%)$ & \multirow[t]{3}{*}{0.861} \\
\hline & $6(15 \%)$ & $5(12.5 \%)$ & $11(13.8 \%)$ & \\
\hline & $4(10 \%)$ & $3(7.5 \%)$ & $7(8.8 \%)$ & \\
\hline \multicolumn{5}{|l|}{ Domicile } \\
\hline Urban & $29(72.5 \%)$ & $30(75 \%)$ & $59(73.8 \%)$ & \multirow[t]{3}{*}{0.954} \\
\hline Rural & $7(17.5 \%)$ & $6(15 \%)$ & $13(16.3 \%)$ & \\
\hline Others & $4(10 \%)$ & $4(10 \%)$ & $8(10 \%)$ & \\
\hline \multicolumn{5}{|l|}{ Socio Economic class } \\
\hline \multirow{3}{*}{$\begin{array}{l}\text { Lower } \\
\text { Middle } \\
\text { Upper }\end{array}$} & $11(27.5 \%)$ & $11(27.5 \%)$ & $22(27.5 \%)$ & \multirow[t]{3}{*}{0.756} \\
\hline & $28(70 \%)$ & $28(70 \%)$ & $56(70 \%)$ & \\
\hline & $1(2.5 \%)$ & $1(2.5 \%)$ & $2(2.5 \%)$ & \\
\hline
\end{tabular}

Table 2- Clinical Data

\begin{tabular}{|c|c|c|c|}
\hline & Cases & Total & P value \\
\hline \multicolumn{4}{|c|}{ Duration of epilepsy } \\
\hline \multirow{4}{*}{$\begin{array}{c}1 \mathrm{yr} \\
1-2 \mathrm{yrs} \\
2-5 \mathrm{yrs} \\
5-10 \mathrm{yrs}\end{array}$} & $13(32.5 \%)$ & $13(32.5 \%)$ & \multirow[t]{4}{*}{0.686} \\
\hline & $22(55 \%)$ & $22(55 \%)$ & \\
\hline & $4(10 \%)$ & $4(10 \%)$ & \\
\hline & $1(2.5 \%)$ & $1(2.5 \%)$ & \\
\hline \multicolumn{4}{|c|}{ Seizure free period } \\
\hline \multirow{4}{*}{$\begin{array}{c}<1 \mathrm{yr} \\
1-2 \mathrm{yrs} \\
2-5 \mathrm{yrs} \\
5-10 \mathrm{yrs}\end{array}$} & $13(32.5 \%)$ & $13(32.5 \%)$ & \multirow[t]{4}{*}{0.562} \\
\hline & $22(55 \%)$ & $22(55 \%)$ & \\
\hline & $4(10 \%)$ & $4(10 \%)$ & \\
\hline & $1(2.5 \%)$ & $1(2.5 \%)$ & \\
\hline
\end{tabular}

Table 3- Cognitive functions Parameters

\begin{tabular}{|c|c|c|c|c|c|c|c|}
\hline & Group & $\mathbf{N}$ & Minimum & Maximum & Mean & StdDeviation & P Value \\
\hline \multirow{2}{*}{$\begin{array}{l}\text { Total } \\
\text { SMMSE } \\
\text { Score } \\
\end{array}$} & Cases & 40 & 23 & 30 & 27.13 & 2.875 & \multirow[b]{2}{*}{0.461} \\
\hline & Control & 40 & 23 & 30 & 27.60 & 2.863 & \\
\hline \multirow{2}{*}{$\begin{array}{ll}\text { BCRS Total } \\
\text { Score }\end{array}$} & Cases & 40 & 1 & 1.6 & 1.165 & .196 & \multirow[t]{2}{*}{0.023} \\
\hline & Control & 40 & 1 & 1.6 & 1.075 & .148 & \\
\hline \multirow{2}{*}{$\begin{array}{l}\text { TMT-B Total } \\
\text { Time }\end{array}$} & Cases & 40 & 200 & 460 & 324.50 & 62.01 & \multirow[b]{2}{*}{0.586} \\
\hline & Control & 40 & 200 & 450 & 317.50 & 52.07 & \\
\hline \multirow[t]{2}{*}{ TMT-B Error } & Cases & 40 & 0 & 3 & .75 & .981 & \multirow[t]{2}{*}{0.023} \\
\hline & Control & 40 & 0 & 2 & .33 & .616 & \\
\hline \multirow{2}{*}{$\begin{array}{ll}\text { DSST } & \text { Total } \\
\text { Time } & \\
\end{array}$} & Cases & 40 & 250 & 530 & 392.75 & 70.529 & \multirow[t]{2}{*}{0.441} \\
\hline & Control & 40 & 260 & 500 & 381.38 & 60.458 & \\
\hline \multirow[t]{2}{*}{ DSST Error } & Cases & 40 & 0 & 5 & 1.28 & 1.301 & \multirow[t]{2}{*}{0.003} \\
\hline & Control & 40 & 0 & 4 & .50 & .906 & \\
\hline
\end{tabular}

